\title{
FERMENTAÇÃO ANAERÓBIA: UMA ALTERNATIVA PARA A PRODUÇÃO DE HIDROGÊNIO1
}

Kenia Gabriela dos Santos², Eduardo De Rossi ${ }^{3}$, Cristie Luis Kugelmeier ${ }^{4}$, Caroline Monique Tietz ${ }^{5}$, Helton José Alves $^{6}$

${ }^{1}$ Aceito para publicação, $2^{\circ}$ trimestre de 2013.

${ }^{2}$ Acadêmica do Curso Superior de Tecnologia em Biocombustíveis da Universidade Federal do Paraná - Setor Palotina - PR, Brasil.

${ }^{3}$ Mestrando em Energia na Agricultura da Universidade Estadual do Oeste do Paraná. Tecnólogo em Biocombustíveis pela Universidade Federal do Paraná - Setor Palotina - PR, Brasil.

${ }^{4}$ Acadêmico do Curso Superior de Tecnologia em Biocombustíveis da Universidade Federal do Paraná - Setor Palotina - PR, Brasil.

${ }^{5}$ Tecnóloga em Biocombustíveis pela Universidade Federal do Paraná - Setor Palotina - Pr, Brasil.

${ }^{6}$ Dr. Química. Professor do Curso Superior de Tecnologia em Biocombustíveis, UFPR - Setor Palotina - PR, Brasil e Professor Permanente do Programa de Pós-graduação em Bioenergia do Estado do Paraná pela UFPR e do Programa de Pós-graduação em Energia na Agricultura da Universidade Estadual do Oeste do Paraná, Cascavel - PR, Brasil

Palavras-chave: biohidrogênio, digestão anaeróbia, sustentabilidade, energia.

\section{Resumo}

O demanda energética e busca a pelo desenvolvimento constantemente em ascensão, tem sido enfrentada de diferentes formas por cada país. O hidrogênio pode ser uma das formas de atender a esta demanda, pode ser resultante de um processo biológico, promovendo desenvolvimento sustentável, contribuindo para o tratamento de resíduos e geração de um biocombustível. O objetivo deste trabalho foi realizar uma revisão sobre o processo biológico fermentativo que vem sendo estudado como uma alternativa para a produção de H2. Neste trabalho, foram avaliados estudos de produção de biohidrogênio com relação a alguns parâmetros do processo como, temperatura, potencial hidrogeniônico, substrato e inóculos. O biohidrogênio é um biocombustível que vem sendo estudado principalmente em países tropicais ou que já possuam uma boa tecnologia de biodigestores pré-estabelecida. Conclui-se que o método biológico tem se mostrado muito atrativo, pois o uso de resíduos para a 
produção de biohidrogênio, a longo prazo, tornará o processo viável economicamente e ambientalmente, facilitando o acesso a este biocombustível.

\section{Introdução}

A demanda energética vem aumentando gradualmente com o desenvolvimento da industrialização, populacional e econômico. Uma das alternativas em relação ao uso das fontes energéticas fósseis é o hidrogênio que é considerado uma energia limpa, um combustível ecológico e com elevado rendimento energético [1].

O Brasil é um país que se destaca pela diversidade de recursos naturais renováveis. Atualmente possui uma matriz energética de $45 \%$ de energia renovável, e no restante dos países esse percentual é em torno de 14\%. Todos esses recursos disponíveis tornam favorável a introdução gradual do hidrogênio, possibilitando uma importante participação mundial deste país sobre as energias renováveis. Por isso, este biocombustível é altamente estratégico para a economia, tecnologia e ambiente [2,3].

O hidrogênio possui duas grandes vantagens: 1) proporcionar a alternativas energéticas; 2) reduzir as emissões de gases de efeito estufa (GEE). Além destas, também promove o desenvolvimento local, gerando empregos e possibilitando o desenvolvimento de um parque industrial competitivo, assegurando-o energeticamente. A produção do hidrogênio pode ser realizada a partir de diversos métodos, os principais caracterizam-se pela produção através de fontes fósseis, como reforma de vapor, craqueamento de gás natural, oxidação de hidrocarbonetos de petróleo e gaseificação de carvão. Estes métodos convencionais requerem aplicação de elevada energia para que o processo ocorra $[4,5]$.

Buscando-se formas de amenizar os impactos ambientes gerados pelos derivados de petróleo, o $\mathrm{H} 2$ pode ser obtido a partir de fontes renováveis como a biomassa [6]. A obtenção deste biohidrogênio ocorre através da atuação de microrganismos que degradam resíduos agroindustriais. Este processo biológico promove um desenvolvimento sustentável e contribui para o tratamento de resíduos. Muitos trabalhos de literatura têm estudado uso de dejetos industriais visando à geração de energia e também o tratamento destes resíduos [7].

O objetivo deste trabalho é efetuar uma breve revisão sobre o processo biológico fermentativo que vem sendo estudado como uma possível alternativa para aplicação nos processos de produção de $\mathrm{H} 2$.

\section{MÉTODOLOGIA}

Revista Brasileira de Energias Renováveis, v. 1, p. 1-12, 2012 
Este estudo constitui-se de uma revisão da literatura sobre as formas de obtenção do hidrogênio via fermentação anaeróbia, caracterizando assim o biohidrogênio, que é considerado uma alternativa promissora para geração de um combustível limpo e renovável.

Os trabalhos investigados para a produção destes, foram consultados através dos bancos de dados Scielo, Science Direct, Taylor e Francis Online, American Chemical Society, etc. As principais palavras-chave utilizadas para a pesquisa foram "hidrogênio" e "processo biológico".

\section{RESULTADOS E DISCUSSÕES}

\section{Hidrogênio}

A produção de $\mathrm{H}_{2}$ é um processo ambientalmente atrativo considerado um combustível renovável alternativo. Uma das vantagens de seu uso é que sua combustão resulta apenas água e a liberação de grandes quantidades de energia, enquanto a combustão de hidrocarbonetos resulta na emissão de GEE [8,9].

Células combustíveis baseadas em hidrogênio já estão inseridas no mercado, e as indústrias automobilísticas mais desenvolvidas estão investindo fortemente no desenvolvimento de carros, ônibus e caminhões que utilizam este tipo de combustível [10].

\section{Fontes e formas para obtenção e produção de hidrogênio}

Há diversos tipos de fontes e métodos para obtenção de $\mathrm{H}_{2}$. Atualmente, essa produção ocorre a partir de fontes fósseis, como gás natural, petróleo e carvão, pelo processo de reforma a vapor, oxidação parcial e gaseificação, respectivamente [5].

De todo o hidrogênio produzido $40 \%$ é proveniente de gás natural, $30 \%$ de hidrocarbonetos, $18 \%$ de carvão e $5 \%$ da eletrólise da água. Porém a produção de $\mathrm{H}_{2}$ através de processos químicos mostra-se pouco sustentável com relação ao balanço energético gerado.

Uma alternativa a estas fontes e métodos é obtenção de biohidrogênio por resíduos orgânicos através de processos biológicos, sendo muito atrativo ambientalmente e é uma tecnologia de baixo custo quando comparada aos métodos convencionais. Além disso, ocorrem em condições de temperatura ambiente e à pressão atmosférica [11].

\section{Processo biológico}


A combinação de produção de $\mathrm{H}_{2}$ com o tratamento de resíduos industriais têm sido muito estuda. $\mathrm{O}$ objetivo da maioria das pesquisas baseadas neste método é a geração de um combustível renovável e a minimização de GEE, uma vez que, o processo fermentativo inclui o ciclo natural do carbono. O maior desafio deste processo é aplicá-lo em escala comercial, e redução dos custos gerados durante a produção $[9,12]$.

Um dos processos com melhor desempenho é com a utilização de bactérias. O processo anaeróbio de geração de biohidrogênio surgiu na década de 1990 e as principais fontes são amidos, materiais celulósicos, resíduos de leite e glicerol [13].

Os principais sistemas para geração de hidrogênio via microbiana são os processos fotoquímicos e fermentativos. O primeiro baseia-se na atuação de microrganismos fotossintéticos, como algas e bactérias fotossintéticas. E o fermentativo consiste em microrganismos produtores de $\mathrm{H}_{2}$ através de anaeróbios facultativos e obrigatórios [14].

Alguns tipos de bactérias e algas atuam na produção de $\mathrm{H}_{2}$. Os três tipos de microrganismos mais utilizados com seus respectivos processos: as cianobactérias, bactérias anaeróbias e bactérias fermentativas. As cianobactérias são responsáveis pela decomposição direta da água em $\mathrm{H}_{2}$ e oxigênio na presença de energia da luz pela fotossíntese; as bactérias fotossintéticas utilizam substratos orgânicos como os ácidos orgânicos; e as bactérias anaeróbicas utilizam substâncias orgânicas como a única fonte de elétrons e de energia, convertendo-os em $\mathrm{H}_{2}$ [15].

\section{Processo fermentativo}

O processo fermentativo biológico da biodigestão anaeróbia de resíduos orgânicos é destaque para a geração de $\mathrm{H}_{2}$, pois a sua aplicação não é tão agressiva em relação aos demais métodos citados anteriormente, além de utilizar matérias-primas renováveis. A biodigestão anaeróbia ocorre com a atuação de microrganismos que convertem compostos orgânicos complexos em metano, gás carbônico, água, gás sulfídrico e amônia [16]. As principais reações bioquímicas que ocorrem são divididas em: hidrólise, acidogênese, acetogênese e metanogênese (Figura 1).

A primeira etapa denominada hidrólise consiste na degradação das moléculas complexas em substâncias mais simples, facilitando a assimilação destas pelas bactérias fermentativas. Para que $\mathrm{o}_{2}$ seja obtido por este processo, é necessário que a reação seja interrompida na fase acidogênica, de modo que impeça que a fase metanogênica ocorra, pois esta acaba consumindo todo o $\mathrm{H}_{2}$ produzido. É nesta fase que os microrganismos acidogênicos realizam a decomposição 
da matéria orgânica, gerando hidrogênio, dióxido de carbono e ácidos gordos voláteis de cadeia curta.

É um processo que apresenta vantagens como: contribuição ambiental, pois os resíduos são utilizados para gerar um combustível renovável; a matéria orgânica é transformada em compostos mais simples, facilitando a sua degradação [17].

As bactérias que realizam hidrólise podem fermentar moléculas orgânicas complexas, dentre estas estão presentes os polissacarídeos, lipídeos e proteínas, podendo resultar em diversificados produtos como ácido acético, hidrogênio, dióxido de carbono, compostos de apenas um carbono, alguns ácidos orgânicos e compostos neutros [18, 19].

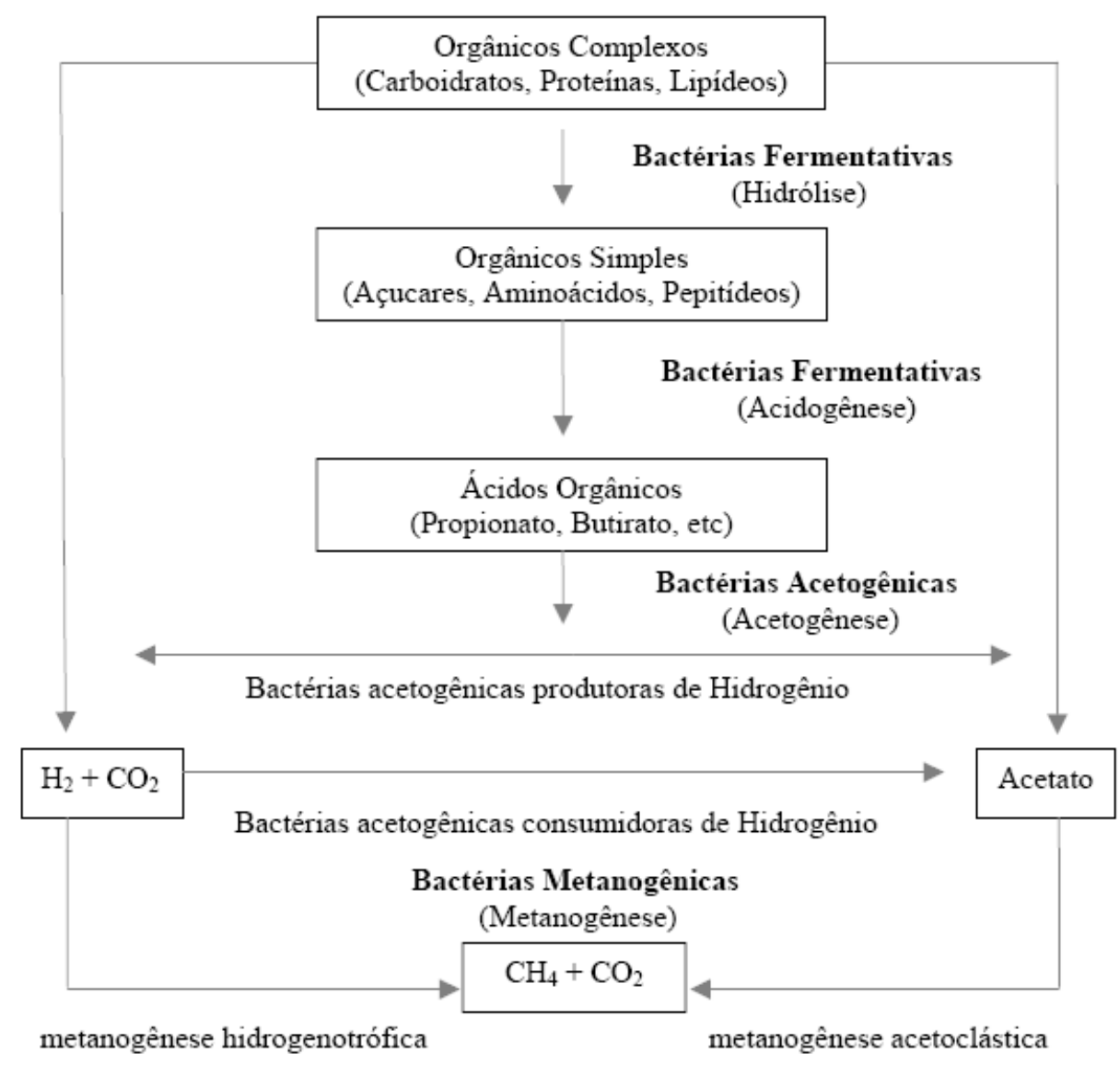

Figura 1: Etapas metabólicas do processo de digestão anaeróbia [19].

As bactérias acidogênicas, são as principais consumidoras dos ácidos graxos voláteis, que são o principal produto das bactérias fermentativas, sendo estas anaeróbias estritas em sua maioria [10]. Bactérias acetogênicas, produzem hidrogênio através de espécies facultativas e estritamente anaeróbias, fermentam ácidos voláteis maiores que o acético, como o butirato e propianato, e compostos neutros maiores que o metanol, decompondo a hidrogênio e acetato [18]. 
E finalmente as bactérias metanogênicas, fermentam hidrogênio e o dióxido de carbono ou compostos constituídos por carbono como, metanol, monóxido de carbono e acetato possuindo como produto de seu metabolismo o metano [19].

\section{Fatores que influenciam a produção de hidrogênio na digestão anaeróbia}

A fermentação requer cuidados com algumas variáveis do processo, como parâmetros nutricionais, ambientais e processamento, visando melhores rendimentos da produção e minimização de custos [21]. A seguir são descritos alguns dos parâmetros mais importantes do processo.

\section{Temperatura}

A temperatura normalmente utilizada é próxima à temperatura ambiente, e isso torna o processo com o balanço energético favorável. Sabe-se que uma temperatura elevada contribui para o aumento da síntese de $\mathrm{H}_{2}$, porém quando muito elevadas ocorre o decréscimo do rendimento da reação [22].

Neves [23] estudou o efeito da diminuição da temperatura sobre o rendimento do processo, realizando ensaios a $30^{\circ}$ e $37^{\circ} \mathrm{C}$ com resíduos da etapa de purificação de biodiesel. Não houve variações significativas, a diminuição de temperatura do processo para $30^{\circ} \mathrm{C}$ mostrou-se vantajosa. $\mathrm{O}$ rendimento de produção foi em média de $2,5 \mathrm{~L} \mathrm{H}_{2} / \mathrm{L}$ e observou-se que a concentração de etanol obtida foi de 5,1 e $3,7 \mathrm{~g} / \mathrm{L}$, para os ensaios realizados a 37 e $30^{\circ} \mathrm{C}$, respectivamente

Wang et al. [24] e Mu et al. [25], estudaram a melhor temperatura no processo fermentativo em batelada utilizando inóculo lodo anaeróbio e sacarose como substrato. A melhor temperatura para cada experimento foi de $35,1^{\circ} \mathrm{C}$ e $35,5^{\circ} \mathrm{C}$, respectivamente. Analisando a temperatura com as mesmas condições WANG e WAN [26] e MU et al. [25] observaram que a melhor temperatura para o processo com substrato de glucose foi de $40^{\circ} \mathrm{C}$ e $41^{\circ} \mathrm{C}$, respectivamente. Já de acordo com Li e Fang [27], a temperatura da fermentação com bactérias mesófilas situa-se próxima a de $37^{\circ} \mathrm{C}$, e de $55^{\circ} \mathrm{C}$ para bactérias termófilas.

\section{Potencial hidrogeniônico}

$\mathrm{O}$ pH é um parâmetro de grande importância para o meio em que ocorre a biodigestão, pois este pode afetar a atividade da hidrogenase, não favorecendo a produção de $\mathrm{H}_{2}$. A faixa de pH que apresenta melhores condições para as atividades das bactérias é entre 6 e 7 [28]. 
O valor de $\mathrm{pH}$ abaixo de 4,5 torna desfavorável o meio para as enzimas hidrogenases, assim como um $\mathrm{pH}$ muito elevado (10-12). A maior parte dos estudos realizados com a fermentação anaeróbia ocorre em modo descontínuo, sem um controle rigoroso do $\mathrm{pH}$, apenas no início do processo quando as hidrogenases começam a atuar [29].

Há algumas divergências com relação ao pH ótimo do processo. Khanal et al. [30] e Trevisan e Monteggia [31], relataram que em reator descontínuo o melhor $\mathrm{pH}$ corresponde a 4,5 e 5,0, respectivamente, enquanto que o relatado por Lee et al. [32] foi de 9,0. E em processo contínuo o $\mathrm{pH}$ ideal encontrado por $\mathrm{Mu}$ et al. [33], foi de 4,2 enquanto para Zhao e Yu [34] corresponde a 7,0. Essa diferença de valores de $\mathrm{pH}$ ideal pode ser em razão das diferenças dos substratos, inóculos e a faixa de $\mathrm{pH}$ analisada [22].

\section{Substratos}

Os substratos submetidos à fermentação são destinados de acordo com a disponibilidade, custos, quantidade de carboidrato e biodegradabilidade. Os mais utilizados no processo de fermentação biológico são sacarose, amido de trigo, óleos vegetais e água residuária da etapa de purificação do biodiesel [35].

Segundo Kapdan e Kargi [9], glicose, sacarose e lactose são os tipos de substratos mais favoráveis para este tipo de processo, já os carboidratos puros são mais caros. Atualmente, alguns estudos tem se concentrado na utilização de resíduos industriais para a produção de $\mathrm{H}_{2}$, visando obter um processo mais econômico. Na tabela 1 podem ser observados alguns substratos pesquisados e a produção de $\mathrm{H}_{2}$ gerada a partir de cada um.

Tabela 1: Produção de Hidrogênio

\begin{tabular}{|c|c|c|}
\hline Substrato & $\begin{array}{c}\text { Produção máxima de } \\
\mathbf{H}_{\mathbf{2}}\end{array}$ & Autores \\
\hline Celulose & $2,18 \mathrm{~mol} / \mathrm{mol}$ de celulose & {$[36]$} \\
\hline Resíduos alimentos & $0,21 \mathrm{~L} / \mathrm{g}$ de resíduo & {$[37]$} \\
\hline Glicerol & $1,12 \mathrm{~mol} / \mathrm{mol}$ de glicerol & {$[38]$} \\
\hline $\begin{array}{c}\text { Água residuária de } \\
\text { biodiesel }\end{array}$ & $\begin{array}{c}1,0 \mathrm{~mol} / \mathrm{mol} \text { de água } \\
\text { residuária }\end{array}$ & {$[38]$} \\
\hline Lactose & $3 \mathrm{~mol} / \mathrm{mol}$ de lactose & {$[39]$} \\
\hline Amido & $67 \mathrm{~mL} / \mathrm{g}$ de amido & {$[40]$} \\
\hline Amido & $194 \mathrm{~mL} / \mathrm{g}$ amido & {$[41]$} \\
\hline
\end{tabular}

Deve-se controlar a quantidade de resíduo aplicada no processo, pois alguns estudos afirmam que uma elevada concentração de substrato pode favorecer a produção de $\mathrm{H}_{2}$, porém uma quantidade excessiva acaba dificultando o processo, gerando decréscimo das bactérias responsáveis pela produção. 
Chen et al. [42] relataram que em seu estudo a melhor concentração foi $4,6 \mathrm{~g}$ de DQO/L e LO et al. (2008) de $40 \mathrm{~g}$ de DQO/L. Essa diferença é possível devido à diferença de inóculos utilizados e os diferentes substratos envolvidos.

\section{Inóculo}

Segundo Fang et al. [43], o processo biológico fermentativo é atrativo não apenas por se tratar de um processo ambientalmente correto, mas também pelo fato de haver uma variedade muito grande de bactérias que atuam neste processo. A produção de hidrogênio via fermentação anaeróbia tem sido muito utilizada com a atuação de microrganismos pertencentes ao gênero Clostridium. De acordo com Neves [23], a espécie Clostridia representa $64,6 \%$ do total de populações estudadas. E essa espécie é facilmente obtida por tratamento calorífico de lamas biológicas.

A Enterobacter aerogenes tem sido estudada para a conversão de glicerol em produtos como $\mathrm{H}_{2}$ e etanol. Isso torna o processo viável, pois além de gerar um combustível renovável $\left(\mathrm{H}_{2}\right)$, o etanol pode ser utilizado [38]. Tanisho [44], avaliou a produção de hidrogênio biológico a partir de compostos orgânicos por fermentação com a aplicação das bactérias Rhodospirillium rubrum, que se mostraram favorável a produção, com uma taxa máxima de produção de $3,0 \mathrm{mmol} / \mathrm{h}$ de $\mathrm{H}_{2}$.

Microrganismos térmofilos também são capazes de atuar na produção de $\mathrm{H}_{2}$, como por exemplo os pertencentes ao gênero Thermoanaerobacterium. Kanay et al. [45], observaram o comportamento da bactéria termófila Thermococcus kodakaraensis, apresentando temperatura ótima de crescimento de $85^{\circ} \mathrm{C}$. A bactéria Clostridium thermolactium realiza as atividades à temperatura de $58^{\circ} \mathrm{C}$ [46].

A escolha do microrganismos envolve o tipo de substrato e também do balanço econômico do processo de produção de $\mathrm{H}_{2}$. Devido às condições ambientais e a diversidade de substancias no resíduo a ser utilizado, há grandes possibilidade de bactérias que consumem o $\mathrm{H}_{2}$ estarem presentes em elevada concentração. Com isso, sugere-se que culturas mistas passem por um pré-tratamento por métodos como choque térmico, aeração, congelamento e descongelamento ou adição de ácido [39, 23].

\section{CONCLUSÕES}

O hidrogênio é uma energia muito promissora para o futuro, e a pesquisa e desenvolvimento do procedimento de obtenção do biohidrogênio tem se intensificado. A 
aplicação do processo fermentativo possibilita o uso de diversos substratos, produzindo $\mathrm{H} 2$ sem a necessidade de iluminação, sendo alguns metabólidos secundários produzidos de grande valor agregado. O método biológico tem se mostrado muito atrativo, pois o uso de resíduos para a produção de hidrogênio, em longo prazo, pode tornar o processo viável economicamente e ambientalmente, facilitando o acesso a este biocombustível. 


\section{REFERÊNCIAS BIBLIOGRÁFICAS}

1. AlBUQUERQUE, M. C. G. Síntese, Caracterização e aplicação de catalisadores heterogêneos para a produção de biocombustíveis. Programa de Pós-Graduação em Química, Universidade Federal do Ceará, 2008.

2. CENTRO DE GESTÃO E ESTUDOS ESTRATÉGICO. Hidrogênio energético no Brasil - Subsídios para políticas de competitividade: 2010 - 2025. Série de Documentos Técnicos, n. 7, 2010.

3. MINISTÉRIO DE MINAS E ENERGIA. Projeto ônibus brasileiro a hidrogênio Tecnologias renováveis para o transporte urbano no Brasil. Disponível em: < http://www.mme.gov.br/programas/onibus_hidrogenio> Acesso em: 11/05/2013.

4. DEMIRBAS, A. Biohydrogen geration from organic waste. Energy Sources, Part A: Recovery, Utilization, and Environmental Effects, v. 30, p. 475-482, 2008.

5. DAS, D.; VEZIROGLU, T.N. Hydrogen production by biological processes: A survey of literature. International Journal of Hydrogen Energy, v. 26, p. 13-28, 2001.

6. JOSHI, A.S.; DINCER, I.; REDDY, B.V. Exergetic assessment of solar hydrogen production methods. International Journal of Hydrogen Energy, v. 25, p. 4901-4908, 2009.

7. YESTIS, M.; GÜNDÜZ, U.; EROGLU, I.; YÜCEL, M.; TÜRKER, L. Photoproduction of hydrogen from sugar refinery. International Journal of Hydrogen Energy, v. 25, p. 1035-1041, 2000.

8. THOMAS, G. Overview of Storage Development DOE Hydrogen Program. Sandia National Laboratories, 2000.

9. KAPDAN, I.K.; KARGI, F. Bio-hydrogen production from waste materials. Enzyme and Microbial Technology, v. 38, p. 559-582, 2006.

10. DAS, D.; VEZIROGLU, T.N. Advances in biological hydrogen production processes. International Journal of Hydrogen Energy, v. 33, p. 6046-6057, 2008.

11. MIZUNO, O.; DINSDALE, R.; HAWKES, F.R.; HAWKES, D.L.; NOIKE, T. Enhancement of hydrogen production form glucose by nitrogen gas sparging. Bioresource Technology, v. 73, p. 59-65, 2000.

12. O-THONG, S.; HNIMAN, A.; PRASERTSAN, P.; IMAI, T. Biohydrogen production from cassava starch processing wastewater by thermophilic mixed cultures. International Journal of Hydrogen Energy, v. 36, p. 3409-3416, 2011.

13. CHONG, M.L.; SABARATNAM, V.; SHIRAI, Y.; HASSAN, M.A. Biohydrogen production from biomass and industrial wastes by dark fermentation. International Journal of Hydrogen Energy, v. 34, p. 3277-3287, 2009.

14. SMITH, G.D.; EWART, G.D.; TUCKER, W. Hydrogen production by cyanobacteria. International Journal of Hydrogen Energy, v. 17, p. 695-698, 1992.

15. HUSSY, I.; HAWKES, F.R.; DINSDALE, R.; HAWKES, D.L. Continuos fermentative hydrogen production from sucrose and sugarbeet. International Journal of Hydrogen Energy, v. 30, p. 471-483, 2007.

16. LETTINGA, G. Sustainable integrated biological wastewater treatment. Water Science and Technology, v. 33, p. 85-98, 1996.

17. SCHRÖDER, U.; SCHOLZ, F. Bacterial batteries. Nature Biotechnology, v. 21, p. 1151$1152,2003$.

18. CHERNICHARO C.A.L.; Reatores anaeróbios: Princípios do tratamento biológico de águas residuárias. v. 5, Belo Horizonte - MG, 1997.

19. SANTOS, J.H.T. Avaliação de um sistema de aquecimento do substrato na digestão anaeróbia de dejetos suínos. Dissertação. Viçosa - MG, 2004. Disponível em: 
<http://www.cetesb.sp.gov.br/userfiles/file/mudancasclimaticas/proclima/file/p ublicacoes/agropecuaria/portugues/tesedejoshumberto2004.pd> Acesso em: $12 / 05 / 2013$.

20. VAN HAANDEL A.C. e LETINGA G., Tratamento anaeróbio de esgotos: um manual para regiões de clima quente. p. 208, Campina grande, 1994.

21. ABDEL-FATTAL, Y.R.; OLAMA, Z.A.L. L-Asparaginase production by Pseudomonas aeruginosa in solid-state culture: Evaluation and optimization of culture conditions using factorial designs. Process Biochemistry, v. 38, p. 115-122, 2002.

22. WANG, J.L.; WAN, W. Comparison of different pretreatment methods for enriching hydrogen-producing cultures from digested sludge. International Journal of hydrogen Energy, p. 2934-2941, 2008.

23. NEVES, L.M.V. Produção de biohidrogênio por bactérias a partir de resíduos fermentescíveis. Dissertação de Engenharia Química e Bioquímica. Faculdade de Ciências e Tecnologia da Universidade Nova de Lisboa, 2009.

24. WANG, G.; MU, Y.; YU, H.Q. Response surface analysis to evaluate the influence of pH, temperature and substrate concentration on the acidogenesis of sucrose-rich wastewater. Journal Biochemical Engineering, v. 23, p. 175-174, 2005.

25. MU, Y.; ZHENG XJ, Yu HQ, Zhu RF. Biological hydrogen production by anaerobic sludge at various temperatures. International Journal of Hydrogen Energy, v. 31, p. 780-785, 2006.

26. hahahah

27. LI, C.L.; FANG, H.H.P. Fermentative hydrogen production from wastewater and solid wastes by mixed cultures. Environmental Science Technology, p. 1-39, 2007.

28. WANG, J.; WAN, W. Factors influencing fermentative hydrogen production: A review. International Journal of Hydrogen Energy, v. 34, p. 799-811, 2009.

29. SILVA, L.S. et al. Hidrogen production from ethanol steam reforming in a solid oxide fuel cell (SOFC) - a theoretical analysis of the system efficiency. Revista Ciências Exatas, v. 15, n. 1, 2009.

30. KHANAL, S.K. et al. Biological hydrogen production: effects of $\mathrm{pH}$ and intermediate products. International Journal of Hydrogen Energy, v. 29, p. 1123-1131, 2004.

31. TREVISAN, V.; MONTEGGIA, L.O. Produção de hidrogênio a partir de efluente da suinocultura e estimativa do seu poder energético. REMADE. Artigo Técnico, 2009.

32. LEE, Y.J.; MIYAHARA, T.; NOIKE, T. Effect of $\mathrm{pH}$ on microbial hydrogen fermentation. Journal of Chemical Technology and Biotechnology, v. 77, p. 694-698, 2002.

33. MU, Y.; WANG, G.; YU, HQ. Response surface methodological analysis on biohydrogen production by enriched anaerobic cultures. Enzyme and Microbial Technology, v.38, p. 905-913, 2006.

34. ZHAO, Q.B.; YU, H.Q. Fermentative H2 production in an upflow anaerobic sludge blanket reactor at various pH values. Bioresource Technology, v. 99, p. 1353-1358, 2008.

35. ALZATE, G.L.M. et al. Comparison of two anaerobic systems for hydrogen production from the organic fraction of municipal solidwaste and syntheticwastewater. International Journal of Hydrogen Energy, v. 32, p. 3141-3146, 2007.

36. LAY, J.J. Biohydrogen generation by mesophilic anaerobic fermentation of microcrystalline cellulose. Biotechnology and Bioengeneering, p. 281-287, 2001.

37. GINKEL, V.; SUNG, S. LAY, J.J. Biohydrogen production as a function of $\mathrm{pH}$ and substrate concentration. Envirinmental Science Technology, p. 4726-4730, 2001.

38. ITO, T. Hydrogen and ethanol production from glycerol-containing wastes discharged after biodiesel manufacturing process. Journal of Bioscience and Bioengineering, 2005. 
39. WANG, J.; WAN, W. Effect of temperature on fermentative hydrogen production by mixed cultures. International Journal of Hydrogen Energy, v. 33, p. 53-92, 2008.

40. ZHANG, T.; LIU, H.; FANG, H.H.P. Biohydrogen production from starch in wastewater under thermophilic condition. Journal of Environmental Management, v. 69, p. 149156, 2003.

41. LIU, G.Z.; CHANG, J.Q. Effects of culture and medium conditions on hydrogen from starch using anaerobic bacteria. Journal of Bioscience and Bioengineering, v. 98, p. 251-256, 2004.

42. CHEN, W.H, CHEN, S.Y.; KHANAL, S.K.; SUNG, S. Kinetic study of biological hydrogen production by anaerobic fermentation. International Association for Hydrogen Energy, v. 31, p. 2170-178, 2006.

43. FANG, H.P.; ZHANG, T.; LIU H. Effect of $\mathrm{pH}$ on hydrogen production from glucose by a mixed culture. Bioresource Technology, v. 82, p. 87-93, 2002.

44. TANISHO, S. Feasibility study of biological hydrogen production from sugar cane by fermentation. In: XI Hydrogen Energy Progress, Germany, 1996.

45. KANAY, T. et al. Continuous hydrogen production by thermophilic archeon Thermococuskodakaraensis KOD1. Journal. Biotechnology, v. 113, p. 76-81, 2005.

46. COLLET, C. et al. Hydrogen Production by Clostridium thermolactium during continuous fermentation of lactose. International Journal of Hydrogen Energy, v. 29, p. 14791485, 2004. 